\title{
Conditioned media from adipose stromal cells limit lipopolysaccharide-induced lung injury, endothelial hyperpermeability and apoptosis
}

\author{
Hongyan Lu ${ }^{1,2,3}$, Christophe Poirier ${ }^{4}$, Todd Cook ${ }^{1,2}$, Dmitry O Traktuev ${ }^{1,2,3}$, Stephanie Merfeld-Clauss ${ }^{1,2,3}$,
} Benjamin Lease ${ }^{2}$, Irina Petrache $e^{2,3,4}$, Keith L March ${ }^{1,2,3}$ and Natalia V Bogatcheva ${ }^{1,2,3^{*}}$

\begin{abstract}
Background: Acute Respiratory Distress Syndrome (ARDS) is a condition that contributes to morbidity and mortality of critically ill patients. We investigated whether factors secreted by adipose stromal cells (ASC) into conditioned media (ASC-CM) will effectively decrease lung injury in the model of lipopolysaccharide (LPS)-induced ARDS.

Methods: To assess the effect of ASC-CM on ARDS indices, intravenous delivery of ASC and ASC-CM to C57BI/6 mice was carried out $4 \mathrm{~h}$ after LPS oropharyngeal aspiration; Evans Blue Dye (EBD) was injected intravenously $1 \mathrm{~h}$ prior to animal sacrifice (48 h post-LPS). Lungs were either fixed for histopathology, or used to extract bronchoalveolar lavage fluid (BALF) or EBD. To assess the effect of ASC-CM on endothelial barrier function and apoptosis, human pulmonary artery endothelial cells were treated with ASC-CM for 48-72 $\mathrm{h}$.

Results: ASC-CM markedly reduced LPS-induced histopathologic changes of lung, protein extravasation into BALF, and suppressed the secretion of proinflammatory cytokines TNFa and IL6. White Blood Cells (WBC) from BALF of LPS-challenged mice receiving ASC-CM had decreased reactive oxygen species (ROS) generation compared to WBC from LPS-challenged mice receiving control media injection. Treatment of pulmonary endothelial monolayers with ASC-CM significantly suppressed $\mathrm{H}_{2} \mathrm{O}_{2}$-induced leakage of FITC dextran and changes in transendothelial resistance, as well as gap formation in endothelial monolayer. ASC-CM exposure reduced the percentage of endothelial cells expressing ICAM-1, and suppressed TNFa-induced expression of E-selectin and cleavage of caspase-3. ASC-CM reduced the endothelial level of pro-apoptotic protein Bim, but did not affect the level of BCl-2, Bad, or Bad phosphorylation.
\end{abstract}

Conclusions: Factors secreted by ASC efficiently reduce ARDS indices, endothelial barrier hyperpermeability, and activation of pro-inflammatory and pro-apoptotic pathways in endothelium.

Keywords: Adipose stromal cells, ARDS, Endothelial barrier, Apoptosis

\section{Background}

ARDS is a serious condition resulting in respiratory failure and increased morbidity and mortality of critically ill patients $[1,2]$. ARDS can be triggered by a variety of pulmonary causes, such as viral infection, pneumonia, aspiration of gastric content, lung contusion, as well as non-pulmonary causes including sepsis, burn injury, multiple trauma, and

\footnotetext{
* Correspondence: nbogatch@iu.edu

'Division of Cardiology, Indiana University, Indianapolis, IN, USA

${ }^{2}$ Indiana Center for Vascular Biology and Medicine and VC-CAST Signature

Center, Indianapolis, IN, USA

Full list of author information is available at the end of the article
}

acute pancreatitis [3]. The pathogenesis of ARDS includes inflammation of the lung parenchyma, infiltration of neutrophils into the airspaces, oxidative stress, disruption of the endothelial and epithelial barriers, damage to the epithelial lining and subsequent lung fibrosis [4]. Despite the fact that the mechanisms contributing to the pulmonary failure are well delineated, more than 20 years of clinical trials show that approaches aiming at the separate components of pathogenesis fail to affect mortality [5]. Currently, ARDS treatment remains primarily supportive. This situation highlights a need for a novel complex therapy, which would both limit the pathogenic mechanisms of ARDS and facilitate

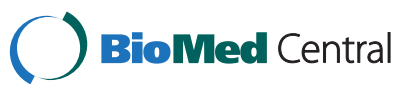


lung repair [6,7]. Cell therapy with adult mesenchymal stromal cells (MSC) may provide such multi-directional therapeutic action, as mesenchymal stromal cells exert pleiotropic effects, including anti-inflammatory and regenerative activities [8].

Initial studies exploring the effects of MSC on lung injury in rodents and explanted human lungs utilized bone marrow-derived mesenchymal stromal cells (MSC). These studies have shown that MSC suppressed lung injury in LPS- [9-11], Escherichia coli- [12], cecal ligation/puncture- [13,14], and bleomycin-induced [15] lung injury models. More recently, there has been increased interest in investigating MSC derived from adipose tissue (ASC) as a therapy for ARDS. The potential advantage of using ASC is their rapid isolation in therapeutic amounts via enzymatic digestion of the autologous adipose tissue harvested by liposuction, unlike MSC, which typically require weeks of propagation for a similar cell yield [16]. Similar to MSC, ASC are effective in inhibiting lung damage in ARDS in LPS- [17-20], cecal ligation/puncture- [21], ventilation- [22] and ischemia-reperfusion-induced [23] lung injury models.

While some studies have reported relatively high level of stem cell engraftment (ranging from 9-16\% of cells administered intravenously) [24] and trans-differentiation into pulmonary cells [25], most studies emphasize stem cellmediated anti-inflammatory effects along with stimulation of phagocytosis and bacterial clearance [9-13,15]. These effects have been attributed to secreted soluble factors from stem cells, and more recently to mitochondrial transfer from stem to host cells [26]. How effective are secreted soluble factors compared to the physical presence of ASC in ARDS therapy is an important question to answer, as the ability to use of-the-shelf conditioned media for therapeutic purposes will have obvious advantages compared to the use of banked or autologous cells.

In the current study, we compared the effects of ASC and ASC-CM on lung injury in a murine model of LPSinduced ARDS and analyzed the effects of ASC-CM on endothelium in vitro. The results of our study provide insight into the mechanisms of ASC beneficial action on inflamed lung, and have implications for the development of new cell-free therapy.

\section{Materials and methods Materials}

E. coli LPS 0127:B8 with the lot activity of 3,000,000 U/mg, and $40 \mathrm{kDa}$ fluorescein isothiocyanate (FITC)-dextran were purchased from Sigma (St. Louis, MO). The antibody recognizing VE-cadherin was from Cayman Chemical (Ann Harbor, MI); antibody to cleaved caspase- 3 was from Cell Signaling (Beverly, MA); antibodies to Bcl-2 and Bad were from Santa Cruz Biotechnology (Dallas, TX); antibodies to phospho-Bad and Bim were from Cell Signaling (Beverly,
MA), antibody to $\beta$-actin was from Sigma (St. Louis, MO). Carboxy-dichlorofluorescein diacetate (carboxy-DCFH-DA), and all reagents used for immunofluorescent staining were obtained from Invitrogen (Carlsbad, CA). All reagents for Flow Cytometry were from BD Biosciences (San Jose, CA).

\section{Animals}

Male C57BL/6 mice were purchased from Harlan (Indianapolis, IN). All animal procedures were approved by Indiana University Institutional Animal Care and Use Committee and conformed to the requirements of Animal Welfare Act.

\section{Cell culture}

All procedures for collecting human adipose tissue were approved by the Indiana University School of Medicine Institutional Review Board. Human ASC (hASC) were isolated from human subcutaneous adipose tissue samples obtained from liposuction procedures as previously described [27] and used at passage 3. Human pulmonary artery endothelial cells (HPAEC) were purchased from Lonza (Walkerville, MD) and used at passages 5-8. Murine ASC (mASC) were isolated from subcutaneous fat from the hip area using a similar procedure. Briefly, fat was excised from the anesthetized animal, minced and digested with $2 \mathrm{mg} / \mathrm{ml}$ collagenase type 1 (Worthington) at $37^{\circ} \mathrm{C}$. Digests were centrifuged at $300 \mathrm{~g}$ to separate floating adipocytes. The pellet containing stromal vascular fraction was re-suspended in basal medium (EBM2 (Lonza)) supplemented with 5\% FBS, filtered through $100 \mu$ nylon filter, and centrifuged again at 300 g. Cells were re-suspended in complete growth medium (EGM2-MV (Lonza)), allowed to adhere to plastic, and propagated in EGM2-MV until 3rd passage at $37^{\circ} \mathrm{C}$ in a humidified atmosphere of $5 \% \mathrm{CO}_{2}-95 \%$ air. Before injection, cells were trypsinized and re-suspended in EBM2 at a concentration of $3 \times 10^{6} \mathrm{cell} / \mathrm{mL}$.

\section{Flow cytometry}

mASC passage 3 were harvested, counted with hemocytometer, and incubated for $20 \mathrm{~min}$ on ice with fluorophore-labeled anti-Sca-1 (positive selection marker), anti-CD31 and anti-CD45 (negative selection markers) IgG. Human ASC were tested for expression of CD13, CD73, CD90, CD105 (positive selection markers), CD31, and CD45 markers. Corresponding IgG were used as isotype controls. Flow cytometry was performed using a Calibur flow cytometer and Cell QuestPro software (BD).

\section{Generation of conditioned media}

The composition of the media used for ASC-CM preparation was chosen depending on the nature of the following assay. Conditioned media for the assessment of the hASC$\mathrm{CM}$ effects on endothelial permeability had to support HPAEC endothelial barrier over the pre-incubation period, 
and therefore was generated using complete growth media EGM2-MV. 50-60\% confluent ASC were incubated with fresh EGM2MV $0.2 \mathrm{~mL} / \mathrm{cm}^{2}$; media was collected $24 \mathrm{~h}$ later, and kept frozen until future analysis. Conditioned media for animal injections had to be FBS-free, and therefore was generated from mASC using basal EBM2 with 0.5\% C57BL/6 mouse serum (Innovative Research, Novi, $\mathrm{MI})$. When mASC-CM was generated, cells were allowed to reach same density as in the experiment when mASC were expanded for injection. Generated mouse ASC-CM $\left(11 \mathrm{ml}\right.$ per $10^{6}$ cells) was concentrated 10 times with $3 \mathrm{kDa}$ cut-off filter (Amicon, Billerica, MS) to render $1.1 \mathrm{ml}$ of product per $10^{6}$ cells. mASC-CM was kept frozen until injection into animals. With this concentration, injection of $0.2 \mathrm{ml}$ of $\mathrm{mASC}-\mathrm{CM}$ is equivalent to the injection of factors generated by 180000 ASC. Corresponding base media (EBM2 with $0.5 \%$ C57BL/6 mouse serum) was subjected to identical manipulations and used for control injections in ASC-CM experiment.

\section{Assessment of ARDS indices}

LPS ( $2 \mathrm{mg} / \mathrm{kg}$ of body weight) or an equal volume of saline was delivered to isoflurane-anesthetized 20-25 g C57BL/6 mice by oropharyngeal aspiration (OA), as described in [20]. Body temperature assessment was performed in alert animals using a rectal probe (YSI Life Sciences, Yellow Springs, $\mathrm{OH}$ ).

In ASC experiments, either 360,000 murine ASC resuspended in basal media EBM2 (passage 3) or equivalent volume of EBM2 $(0.1 \mathrm{~mL})$ were injected into tail vein $4 \mathrm{~h}$ after LPS administration. In ASC-CM experiments $0.2 \mathrm{~mL}$ of concentrated ASC-CM or corresponding control media were injected. Twenty-four or $48 \mathrm{~h}$ later, animals were sacrificed for analysis. For the assessment of vascular leak

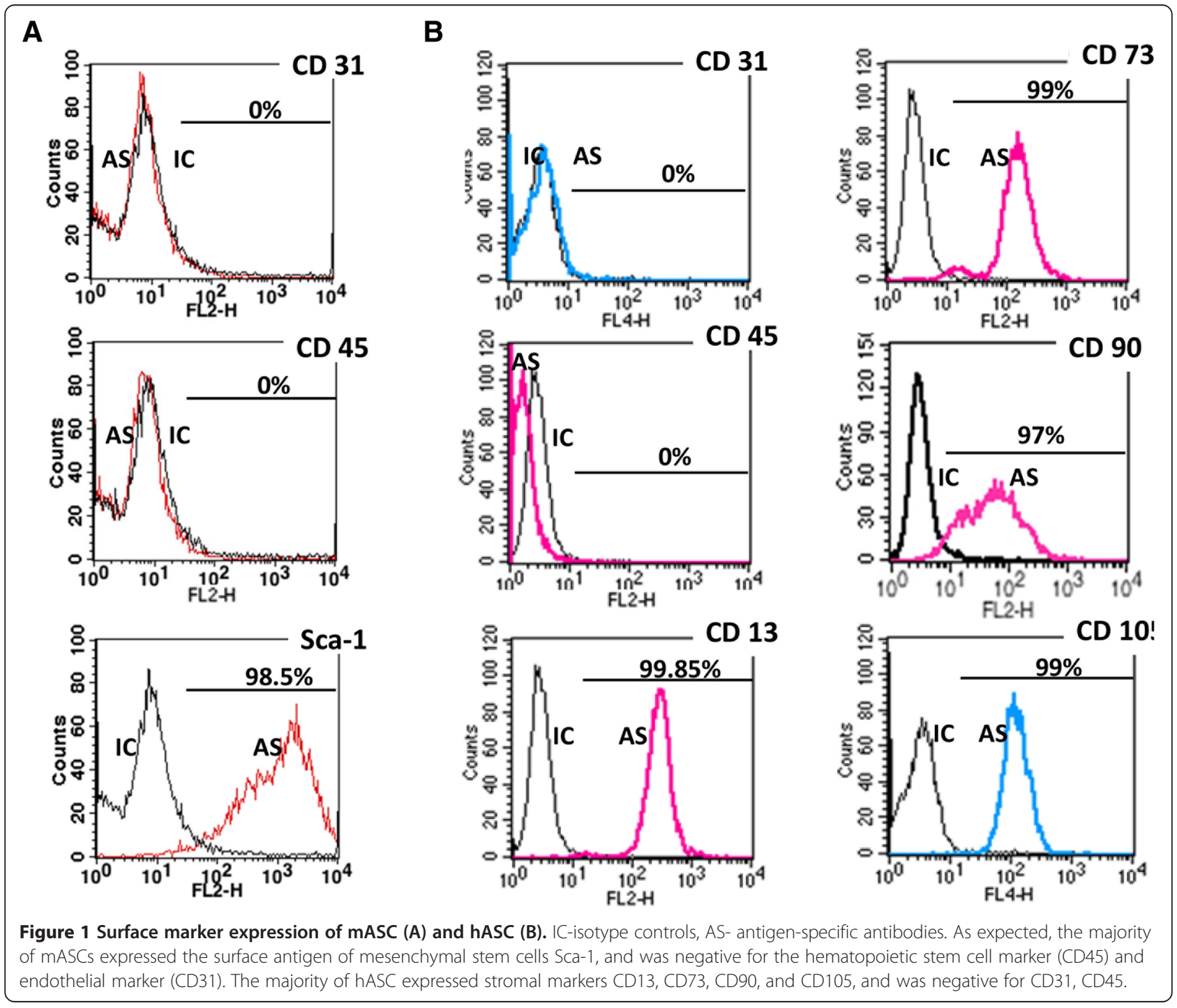


and lung inflammation, EBD- albumin conjugate $(0.5 \%$ EBD/ 4\% BSA solution in saline) was administered in the tail vein $(30 \mathrm{mg} / \mathrm{kg}) 1 \mathrm{~h}$ prior to experiment termination. The chest cavity was opened under anesthesia and blood was sampled by cardiac puncture to determine level of circulating EBD. After nicking left atrium and severing abdominal aorta and vena cava, lungs were washed from blood by injecting saline via the right ventricle. Bronchoalveolar lavage fluid (BALF) was obtained by flushing lungs via trachea with $3 \mathrm{~mL}$ ice-cold PBS. Lungs were excised and homogenized in formamide to extract EBD $\left(18 \mathrm{~h}, 60^{\circ} \mathrm{C}\right)$; optical density was determined at 620 and $750 \mathrm{~nm}$. Extravasated EBD concentration was calculated using a standard curve and normalized to plasma EBD level. BALF was centrifuged at $600 \mathrm{~g}$ to sediment cells; supernatant was snap-frozen for future ELISA and protein content analyses. Pellet was subjected to red cell lysis; remaining cells were separated by cytospin and stained with Diff Quick staining kit (ThermoFisher Scientific, Waltham, MA). Cells were identified under Nikon microscope 40x objective; total of 300 cells were counted on each slide. For immunohistochemistry, lungs were perfused with $4 \%$ formaldehyde/agarose solution, embedded in paraffin, sectioned and analyzed with Nikon microscope (10x magnification objective).

\section{ELISA analyses}

Mouse Quantikine ELISA kits were from R\&D Systems (Minneapolis, MN). Undiluted BALF stored at $-80^{\circ}$ was used to determine concentrations of TNF $\alpha$, IL-6, IL-10, MIP-2, and VEGF; all analyses were run in duplicate. Cytokine content in BALF was determined by multiplying cytokine concentration $(\mathrm{pg} / \mathrm{mL})$ by the exact volume of BALF obtained from a specific animal (approximately $3 \mathrm{~mL}$ ).

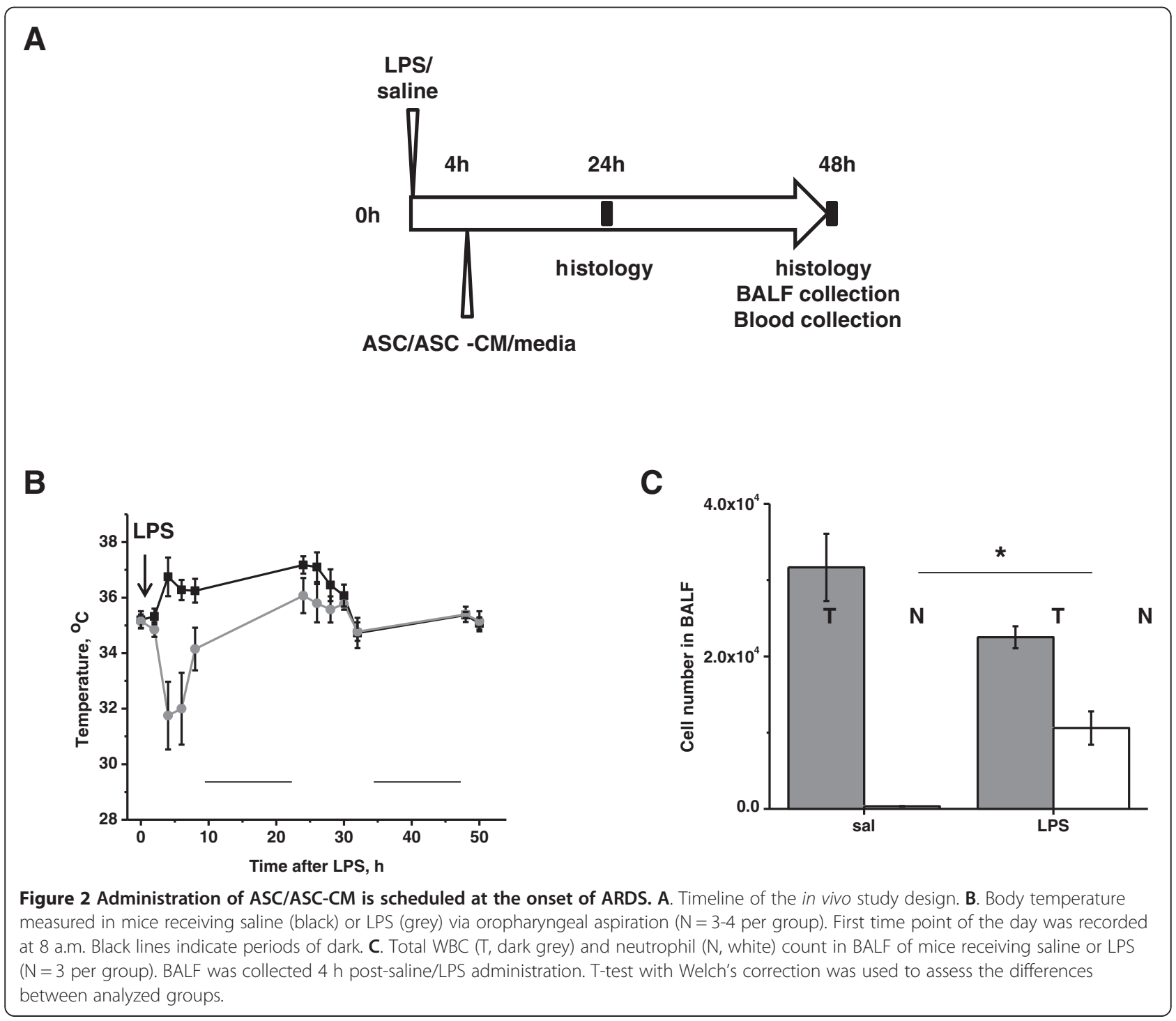




\section{Assessment of ROS generation}

The method for the measurement of oxidative activation of neutrophils was based on the ROS-dependent oxidation of carboxy-DCFH-DA to carboxy-DCF [28]. Cells from BALF of LPS- and LPS/ASC-CM treated mice were placed in wells of 96-well plate $(60,000$ cells per well), pre-loaded with $12.5 \mu \mathrm{g} / \mathrm{ml}$ carboxy-DCFH-DA, and then stimulated with $1 \mu \mathrm{g} / \mathrm{ml}$ LPS for $20 \mathrm{~h}$. Wells with no cells containing the same concentration of dye were used as controls. Fluorescence was read in the FITC channel of fluorometer/plate reader. All assays were run in triplicate.

\section{Measurement of transendothelial permeability}

Permeability of HPAEC monolayers for FITC-dextran was measured using $0.4 \mu$ polyester trans-well inserts (Costar) as described in [29]. Briefly, HPAEC were plated on collagen-coated inserts, whereas ASC or NHDF were plated on the bottom of wells. HPAEC were allowed to reach confluency. Alternatively, HPAEC were pretreated with unconcentrated ASC or NHDF conditioned media mixed with EGM2MV (1:1) for $72 \mathrm{~h}$. Media were changed to EBM-2 (Lonza) $1 \mathrm{~h}$ prior to FITC-dextran loading. FITC-dextran was added to the top chamber to a final concentration $1.75 \mathrm{mg} / \mathrm{mL}$; immediately after, monolayers were stimulated with $0.25 \mathrm{mM} \mathrm{H}_{2} \mathrm{O}_{2}$. After $2 \mathrm{~h}$, media was sampled from the bottom chamber and analyzed for FITC-dextran fluorescence. All analyses were run in quadruplicate.

Transendothelial electrical resistance (TER) was measured using the highly sensitive biophysical assay with an electrical cell-substrate impedance sensor (ECIS) (Applied Biophysics, Troy, NY) as described previously [29]. HPAEC were plated on gold microelectrodes in EGM2MV; then exposed to the un-concentrated conditioned media/EGM2MV mixture (1:1) for $72 \mathrm{~h}$. At the

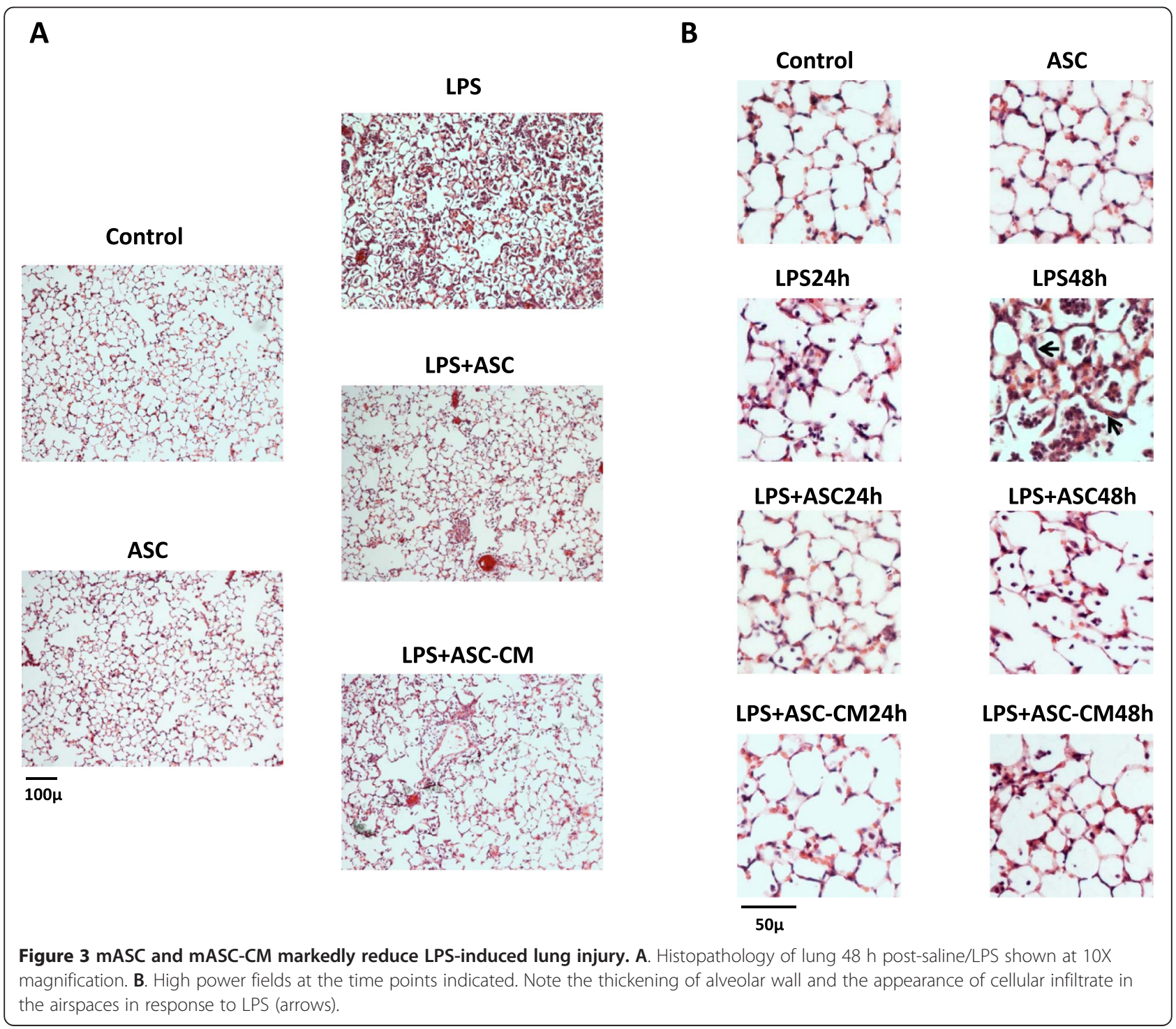


end of pre-incubation period, resistance of monolayers reached 1000-1200 Ohms, evident of monolayer confluence. Media were changed to basal media $1 \mathrm{~h}$ prior to the beginning of the TER recording. $30 \mathrm{~min}$ after the start of recording, monolayers were stimulated with $0.25 \mathrm{mM} \mathrm{H}_{2} \mathrm{O}_{2}$.

\section{HPAEC imaging}

For immunofluorescence experiments, HPAEC monolayers were plated on gelatin-coated coverslips and grown to confluence. Cells were exposed to the un-concentrated conditioned media mixed with EGM2-MV (1:1) for $72 \mathrm{~h}$; media were changed to EBM2 $1 \mathrm{~h}$ prior to the beginning of the experiment. After $\mathrm{H}_{2} \mathrm{O}_{2}$ stimulation, cells were fixed, permeabilized and stained with VE-cadherin-specific antibodies and Alexa594-conjugated phalloidin. Coverslips were viewed and photographed using Nikon fluorescent microscope (40x objective).
Assessment of VCAM, ICAM-1, and E-selectin expression HPAEC grown in 6 well plates were exposed to the unconcentrated conditioned media mixed with EGM2-MV (1:1) for $72 \mathrm{~h}$; media were changed to EBM2 $1 \mathrm{~h}$ prior to the beginning of the experiment. $4 \mathrm{~h}$ after TNF $\alpha /$ vehicle control stimulation, cells were harvested and incubated with fluorescently labeled IgG against CD54/ICAM-1 (eBioscience, San Diego, CA), CD62E/E-selectin (Biolegend, San Diego, CA), and CD106/VCAM (BD) on ice for $30 \mathrm{mi}-$ nutes. Labeled cells were analyzed with Guava 8HT flow cytometer ((EMD Millipore, Billerica, MA).

\section{Western immunoblotting}

HPAEC grown in 12-well plates were exposed to the unconcentrated conditioned media mixed with EGM2-MV (1:1) for 48-72 $\mathrm{h}$; media were changed to EBM2 $1 \mathrm{~h}$ prior to the beginning of the experiment. After $4 \mathrm{~h}$ stimulation with TNFo, cells were rinsed with ice-cold

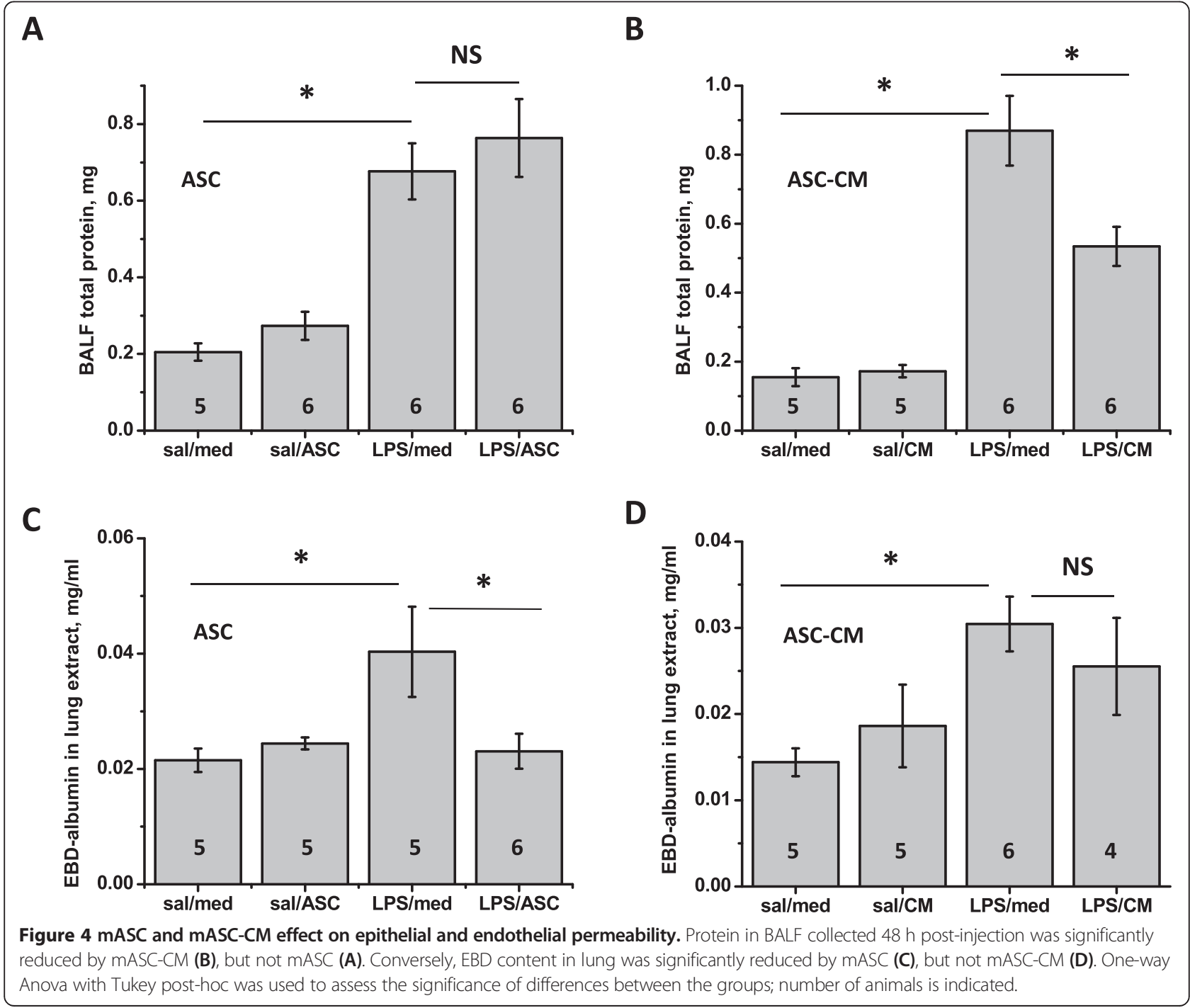


PBS and lysed with 1\% SDS containing buffer. Protein extracts were separated on 4-20\% gels and transferred to nitrocellulose membrane. After staining with specific antibodies, membranes were developed and scanned using BioRad imaging system.

\section{Statistical analysis}

Quantitative data are presented as mean \pm SEM, unless otherwise indicated. Statistical analysis was performed by t-test, t-test with Welch's correction (unequal variance), One-way ANOVA with Tukey post-hoc or Repeated Measures One-way ANOVA using GraphPad Prizm6 or Origin 8.0 software. Shapiro-Wilk test was used to confirm that data were drawn from a normally distributed population.
A probability value of $<0.05$ was considered statistically significant.

\section{Results}

Flow cytometric analyses of ASC surface markers

Both murine and human ASC used in our study were produced by propagation of the cell fraction adherent to plastic under standard culture conditions. mASC and hASC demonstrated typical size, spindle shape, and morphology in culture consistent with adipose stem cells. mASC as well as hASC were evaluated with respect to their surface marker phenotype at passage 3 . mASC were positive for Sca-1, one of the markers routinely used to characterize mesenchymal stem cells of

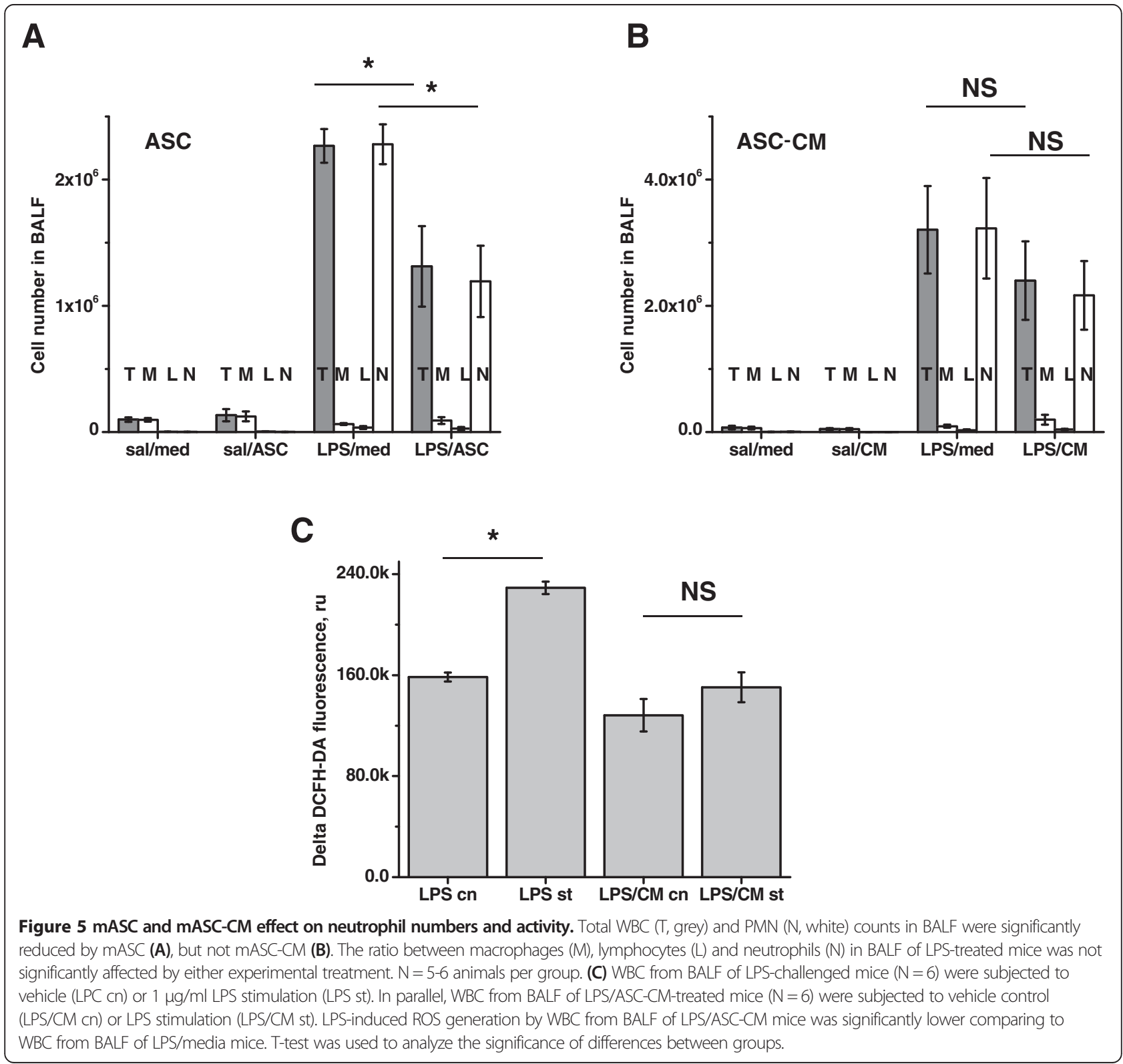


murine origin [30], and negative for the endothelial cell marker CD31 and the marker of cells of hematopoietic origin CD45 (Figure 1A). Similarly, analysis of hASC at passage 3 demonstrated positive staining for the stromal markers CD13, CD73, CD90 and CD105 and negative staining for CD31 and CD45 (Figure 1B).

\section{Study design}

LPS or saline were delivered into lungs through oropharyngeal aspiration (Figure 2A). Intravenous ASC, ASC-CM or control media injections were performed $4 \mathrm{~h}$ after LPS delivery. This protocol was designed to schedule the ASC administration concurrently with the onset of ARDS, identified by peak of hypothermia at $4 \mathrm{~h}$ following LPS administration (Figure 2B) and by the first presence of neutrophil infiltration in BALF (Figure 2C).

\section{Effect of ASC or ASC-CM on lung histopathology following LPS administration}

Hematoxylin and eosin staining of the lung sections revealed no apparent signs of inflammatory response in saline-treated lungs of mice which received ASC or control media injection (Figure 3A,B). LPS triggered lung inflammation, which was evident at $24 \mathrm{~h}$ and severe at $48 \mathrm{~h}$. In mice receiving control media injection, LPS caused marked infiltration of neutrophils and red blood cells into the lung interstitium and airspaces, as well as swelling of the alveolar walls. In contrast, systemic delivery of ASC or ASC-CM reduced septum thickening and suppressed accumulation of cells and debris in the alveolar sacs (Figure 3).

\section{ASC and ASC-CM effects on lung permeability and neutrophil infiltration}

Assessment of total protein content in BALF showed a significant increase of protein level in response to LPS administration (Figure 4 A,B). While ASC treatment had no effect on LPS-induced protein increase in BALF, ASC-CM treatment markedly suppressed the LPS-induced protein increase $48 \mathrm{~h}$ post-injection. On the contrary, ASC were able to suppress LPS-induced increase in EBD extravasation (Figure 4C), whereas ASC-CM effect was not significant (Figure 4D).

Assessment of total WBC count in BALF showed that the number of cells in airspaces increased dramatically in response to LPS stimulation (Figure 5A,B). Whereas resident lung macrophages comprised the majority of cells in
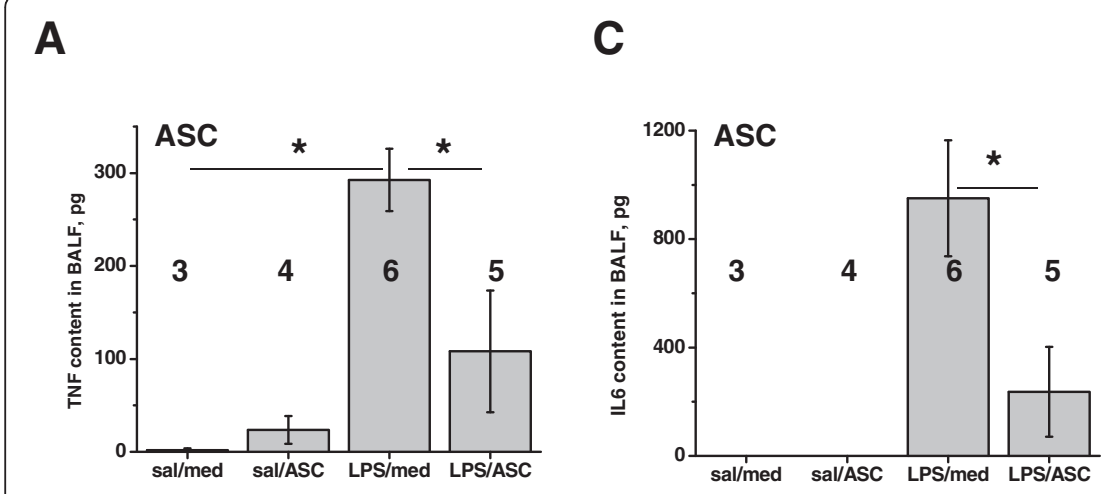

E

\section{B}
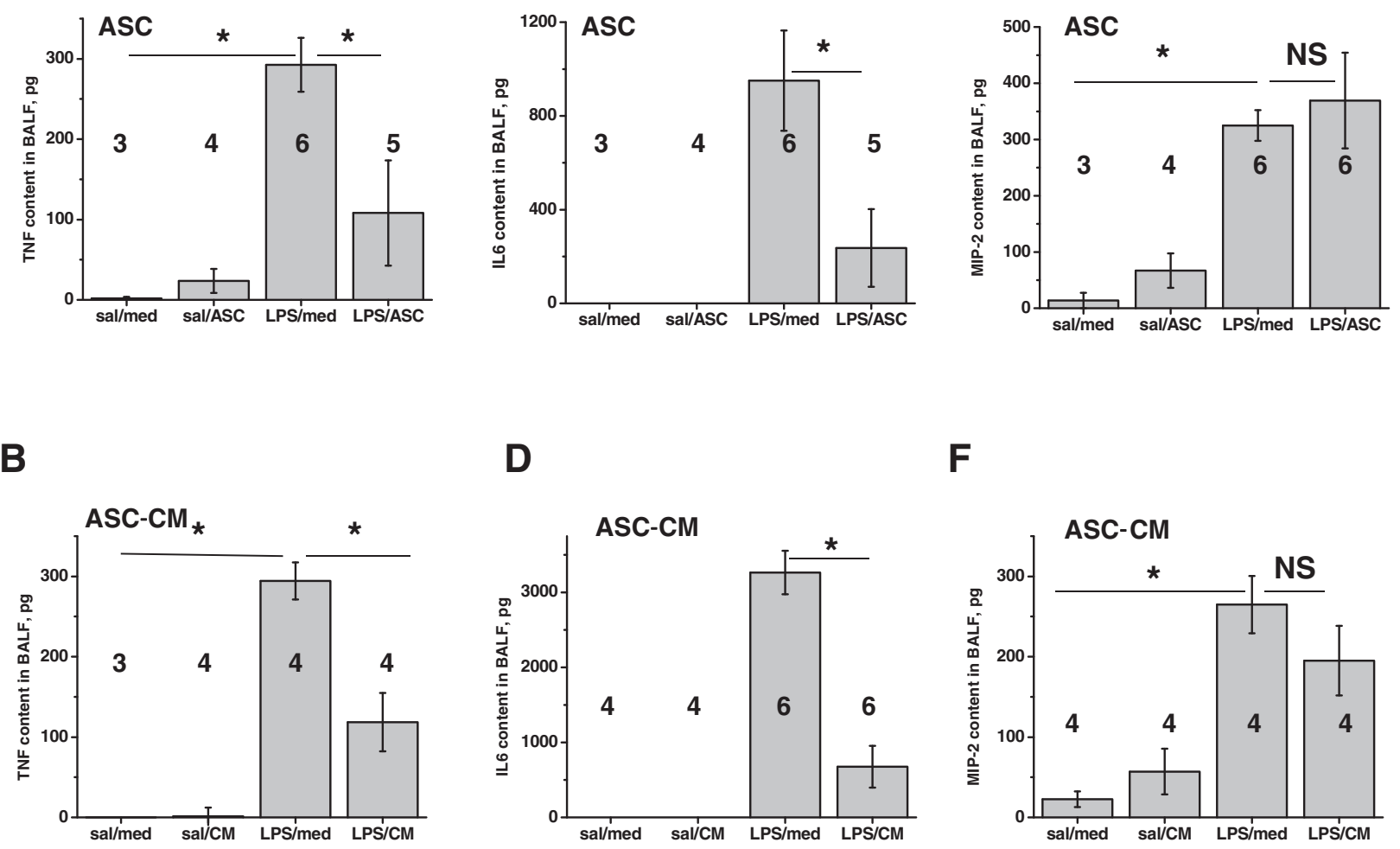

$\mathbf{F}$

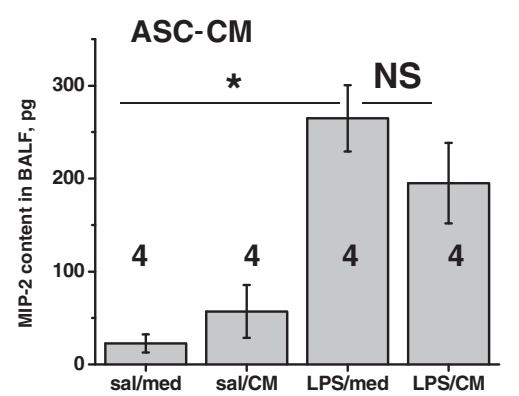

Figure 6 mASC and mASC-CM effect on pro-inflammatory cytokines in BALF. mASC and mASC-CM reduced the level of TNFa and IL6 (A-D), but not MIP-2 (E-F). One-way Anova with Tukey post-hoc was used to assess the significance of differences between the groups; number of animals is indicated. 
BALF from saline lungs, neutrophils were the dominant cell type in BALF from LPS-challenged lungs. Although ASC or ASC-CM treatment did not shift the overall neutrophil/macrophage balance (Figure 5A,B), a significant suppression of total WBC count was evident in LPS mice receiving ASC injection (Figure 5A). A similar trend was observed in mice receiving ASC-CM, but did not reach significance at $48 \mathrm{~h}$ post-injection (Figure $5 \mathrm{~B}$ ). To further characterize possible mechanisms of ASC-CM-mediated lung injury limitation, we compared the ability of BALF WBC, obtained from LPS- or LPS/ASC-CM-receiving mice, to generate ROS. The method for the measurement of neutrophils oxidative activity was based on ROSdependent oxidation of DCFH-DA (non-fluorescent) to highly fluorescent DCF. Isolated BALF WBC were tested for their abilities to oxidize DCFH-DA in response to LPS stimulation in vitro. We observed that WBC from mice receiving LPS can be further induced by LPS stimulation, whereas WBC from mice receiving LPS/ASC-CM no longer respond to LPS stimulation (Figure $5 \mathrm{C}$ ), suggesting that mice exposure to ASC-CM leads to lung recruitment of neutrophils with a reduced potential for oxidative response.

\section{ASC and ASC-CM effects on accumulation of pro- and} anti-inflammatory cytokines and pro-angiogenic factor in BALF

To determine the effect of ASC and ASC-CM on inflammation progression/resolution, we assessed the level of the pro-inflammatory cytokines TNF $\alpha$, IL6, and MIP-2, and anti-inflammatory IL10 in BALF. LPS caused marked increase in the level of TNF $\alpha$, IL6 and MIP-2 (Figure 6A-F). Forty-eight hours after cell or conditioned media injection,

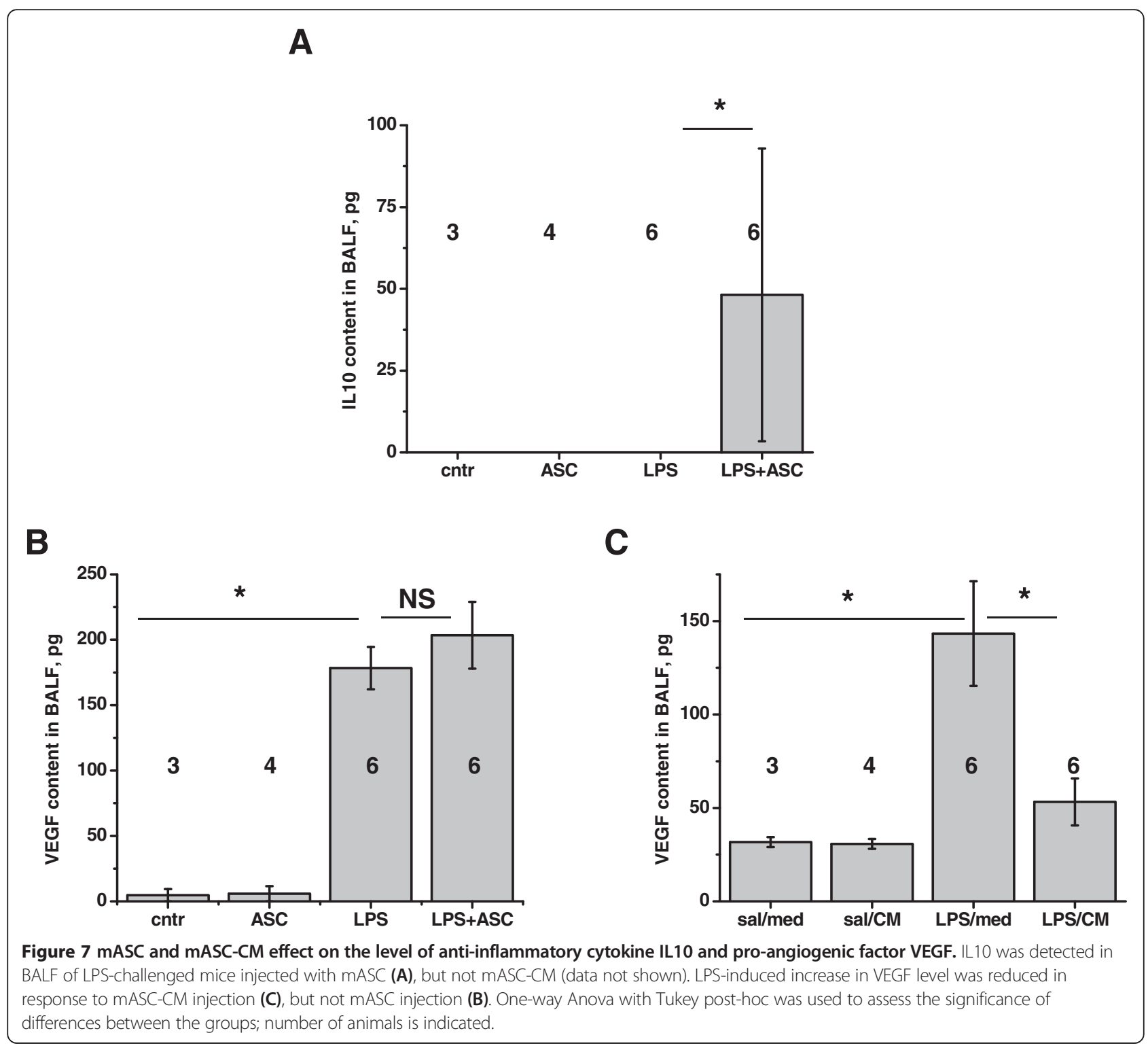


LPS-induced increase in TNF $\alpha$ and IL6 levels was suppressed by both agents, whereas the increase in MIP-2 level was not affected significantly. The level of antiinflammatory IL10 remained below detection in control mice as well as mice challenged with LPS. Significant increase in BALF IL10 content was observed in response to ASC (Figure 7A), but not ASC-CM (data not shown). Interestingly, the LPS-induced level of VEGF in BALF was nonsignificantly increased in ASC-treated mice, but markedly suppressed in ASC-CM-treated mice (Figure 7B-C).

\section{ASC and ASC-CM effects on endothelial permeability in vitro}

To further analyze mechanisms underlying ASC and ASC-CM effects on lung permeability, we directly assessed
ASC/ASC-CM effects on monolayer barrier function of well-characterized human pulmonary endothelial cell line HPAEC. Since recently it was suggested that syngeneic ASC therapy has more potent effect than xenogeneic therapy [20], we tested the effect of hASC/hASC-CM on the permeability of human pulmonary endothelium. First, HPAEC monolayers were grown on collagen-coated polyester inserts in the presence of hASC or NHDF (as a nonstem control) in the lower chamber. Prior to analysis, inserts were transferred to fresh wells to avoid the possibility of direct ROS scavenging by hASC/NHDF. The top chamber was loaded with FITC-dextran, and monolayers were stimulated with $\mathrm{H}_{2} \mathrm{O}_{2}$, the edemagenic product of the neutrophil oxidative burst. We observed marked HPAEC barrier dysfunction in response to $\mathrm{H}_{2} \mathrm{O}_{2}$, which

\section{A}

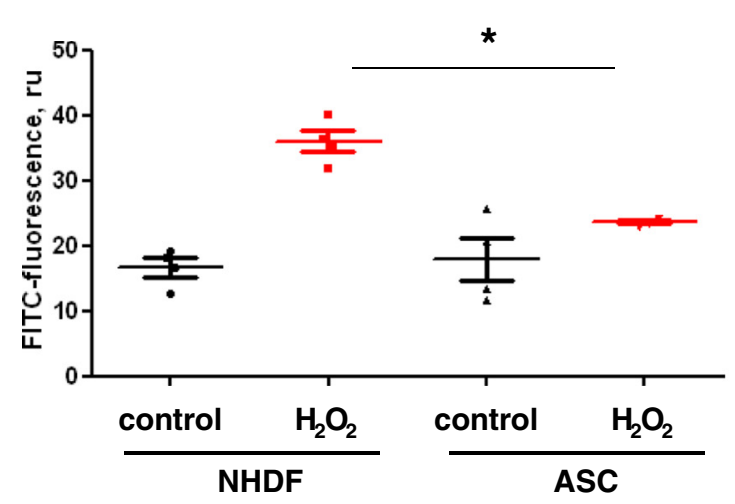

B

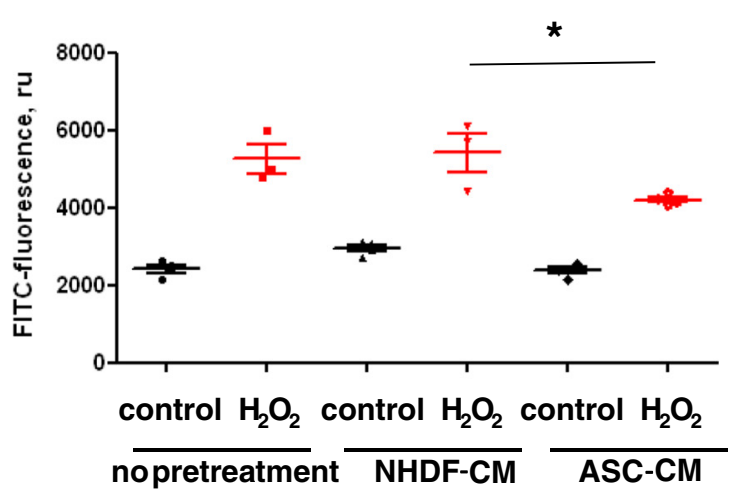

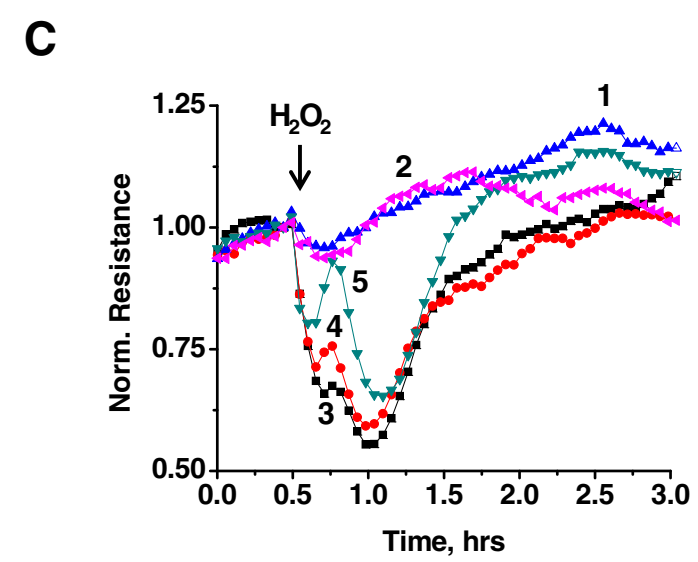

Figure 8 hASC and hASC-CM preserve HPAEC transendothelial permeability. HPAEC were grown on polyester inserts (A-B) or on gold electrodes of ECIS arrays (C) in the absence/presence of NHDF/hASC (A), or NHDF/hASC conditioned media (B-C). HPAEC were removed from the contact with cells/media; then stimulated with $250 \mu \mathrm{M} \mathrm{H}_{2} \mathrm{O}_{2}$. T-test with Welch's correction was used to assess the differences between analyzed groups. NHDF and NHDF-CM were used for comparison as a non-stem cell/conditioned media control. (C) Shown are the means of 3 parallel recordings for each pretreatment/stimulation: 1) unstimulated HPAEC pretreated with NHDF-CM; 2) unstimulated HPAEC pretreated with hASC-CM; 3) stimulated with $\mathrm{H}_{2} \mathrm{O}_{2}$ HPAEC which were not pretreated with $\mathrm{CM}$; 4) stimulated with $\mathrm{H}_{2} \mathrm{O}_{2}$ HPAEC which were pretreated with NHDF-CM; 5) stimulated with $\mathrm{H}_{2} \mathrm{O}_{2}$ HPAEC pretreated with hASC-CM. Repeated measures One-way ANOVA showed significant differences between response of NHDF-CM-pretreated cells and response of ASC-CM pretreated cells. Preincubation of endothelial monolayers with hASC or hASC-CM reduced $\mathrm{H}_{2} \mathrm{O}_{2}$-induced hyperpermeability of HPAEC to FITC-dextran (A-B) or to ions (C). 
was significantly attenuated in monolayers grown in the presence of hASC (Figure 8A). We next pretreated HPA EC monolayers with either hASC-CM or NHDF-CM. Similar to HPAEC grown in the presence of hASC, HPAEC grown in the presence of hASC-CM responded to $\mathrm{H}_{2} \mathrm{O}_{2}$ with less barrier dysfunction (Figure $8 \mathrm{~B}$ ); this stabilizing effect was not seen with NHDF-CM. To further characterize the hASC-CM-mediated stabilization of HPAEC barrier, we assessed transendothelial electrical resistance (TER). HPAEC grown on gold electrodes were pretreated with hASC-CM or NHDF-CM; then stimulated with $\mathrm{H}_{2} \mathrm{O}_{2}$. Control monolayers responded to $\mathrm{H}_{2} \mathrm{O}_{2}$ with marked reduction of TER, which was restored within $3 \mathrm{~h}$. NHDF-CM-pretreated monolayers displayed a similar response curve, whereas hASC-CM-pretreated monolayers had a significantly attenuated barrier dysfunction in response to $\mathrm{H}_{2} \mathrm{O}_{2}$ (Figure $8 \mathrm{C}$ ). Immunofluorescent microscopy of NHDF-CM-pretreated HPAEC showed that $\mathrm{H}_{2} \mathrm{O}_{2}$ caused marked rearrangement of the actin cytoskeleton along with distortion of junctional organization and gap formation in endothelial monolayers (Figure 9, arrowheads). hASC-CM-pretreated HPAEC displayed less severe changes in response to $\mathrm{H}_{2} \mathrm{O}_{2}$, with attenuated gap formation.

\section{ASC-CM effect on the expression of ICAM-1 and E-selectin in endothelium}

To ascertain whether hASC-CM anti-inflammatory effect is dependent on the suppression of endothelial expression of leucocyte receptors, we assessed the level of expression of VCAM, ICAM-1, and E-selectin in naïve and TNF $\alpha$-stimulated HPAEC. Low percentage of unstimulated cells appeared positive for VCAM (data not shown) and E-selectin, whereas expression of ICAM-1 was detected in at least $70 \%$ cells (Figure 10). TNF $\alpha$ caused dramatic increase in the percentage of VCAM(data not shown) and E-selectin-positive cells, also increasing ICAM-1 expression evident by the shift in ICAM-1 geo-mean value. HPAEC exposed to hASC-CM did not show significant difference in the expression of VCAM either in absence or presence of TNF (data not shown). Percentage of ICAM-positive cells detected in the absence of TNF $\alpha$ was significantly suppressed by hASC-CM treatment; however, this effect was not detected in the presence of TNF $\alpha$. On the contrary, Eselectin expression (evident by geo-mean) was significantly suppressed in the presence of TNF $\alpha$.

\section{hASC-CM effect on the activation of pro-apoptotic pathways in endothelium}

To elucidate whether anti-inflammatory effects of hASC$\mathrm{CM}$ are mediated by the suppression of pro-apoptotic changes in endothelium, we assessed the level of caspase- 3 cleavage in response to TNF $\alpha$ (Figure 11). TNF $\alpha$ induced cleavage and activation of caspase- 3 evident at $4 \mathrm{~h}$. HPAEC pretreated with hASC-CM showed a marked reduction of cleaved caspase-3 level in response to TNFa. As caspases activation is known to be regulated by pro-apoptotic and anti-apoptotic members of Bcl2 family [31], we next investigated whether levels of these proteins are affected by hASC secreted factors. Levels of anti-apoptotic protein $\mathrm{Bcl} 2$ and pro-apoptotic protein Bad did not change in HPAEC preconditioned with hASC-CM. We did not observe consistent increase in Bad phosphorylation (evident of Bad deactivation) in response to hASC-CM pretreatment. However, exposure to hASC-secreted factors markedly reduced the level of pro-apoptotic protein Bim.

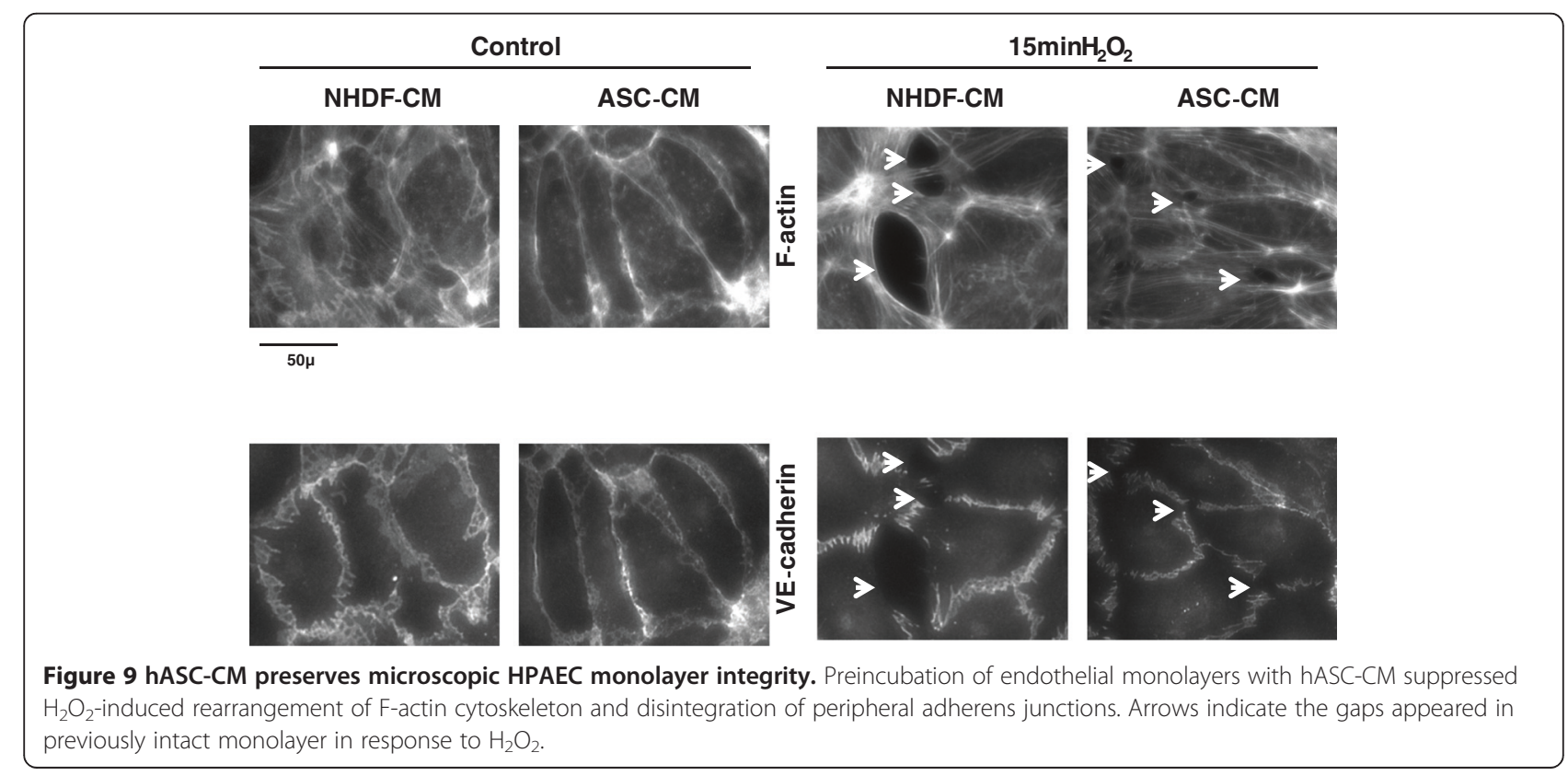




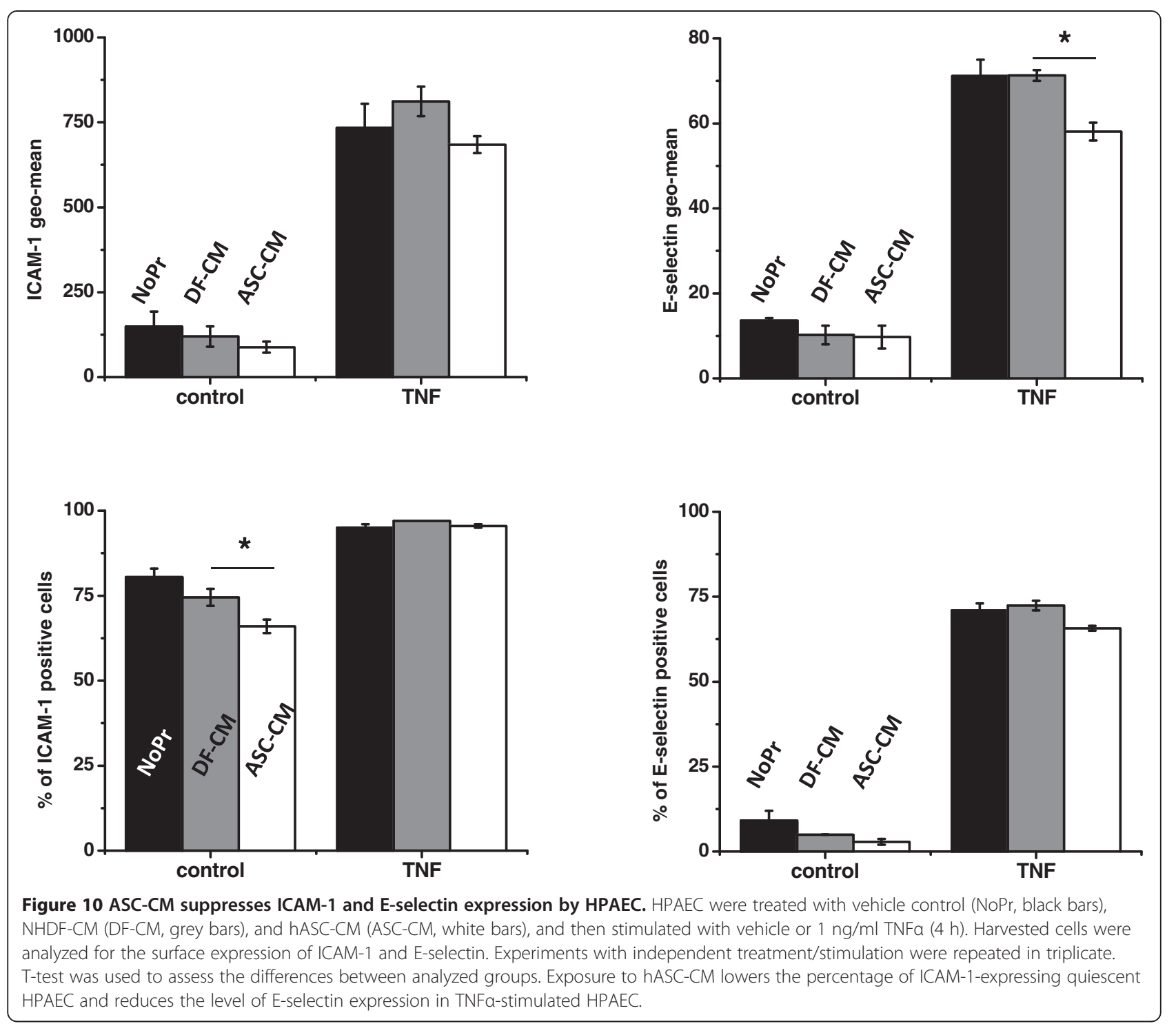

\section{Discussion}

Here, we demonstrate for the first time that administration of ASC-CM reduces indices of lung injury in the LPS-induced ARDS model. Although autologous ASC can be easily isolated from liposuction material within hours of the patient admission to ICU [16], the ability to avoid this procedure and use an "off-the-shelf" therapeutic product could be a significant advantage for the treatment of critically ill patient. Another potential advantage of the use of conditioned medium is the absence of concerns associated with the possibility of cells homing toward preexisting tumors [32] or causing thromboemboli [33].

Previously, we have demonstrated that ASC-CM administration is able to prevent and reverse brain hypoxicischemic injury [34]. Here, we assessed whether ASC-CM would exhibit an ability to prevent development of LPSinduced lung injury. Our study showed that a single administration of ASC-CM limited lung inflammatory histological changes, protein extravasation to airspaces, accumulation of inflammatory mediators TNF $\alpha$ and IL6 in BALF, and the ability of BALF WBC to generate ROS. One limitation of this study was that ARDS indices were analyzed via procedures requiring animal termination, which limits the assessment of precise kinetics of the response. We observed that ASC-CM-mediated suppression of LPSinduced neutrophil infiltration showed a trend parallel to ASC, yet did not reach significance at $48 \mathrm{~h}$ post-injection. We also did not detect the suppression of LPS-induced vascular leakage at this time point. We can only speculate whether the suppression of LPS-induced neutrophil infiltration and vascular leakage by ASC-CM is significant at the earlier time points in our model; however, it is to be expected that sustained retention of cells in the inflamed lung would elicit more profound effects than the bolus injection 


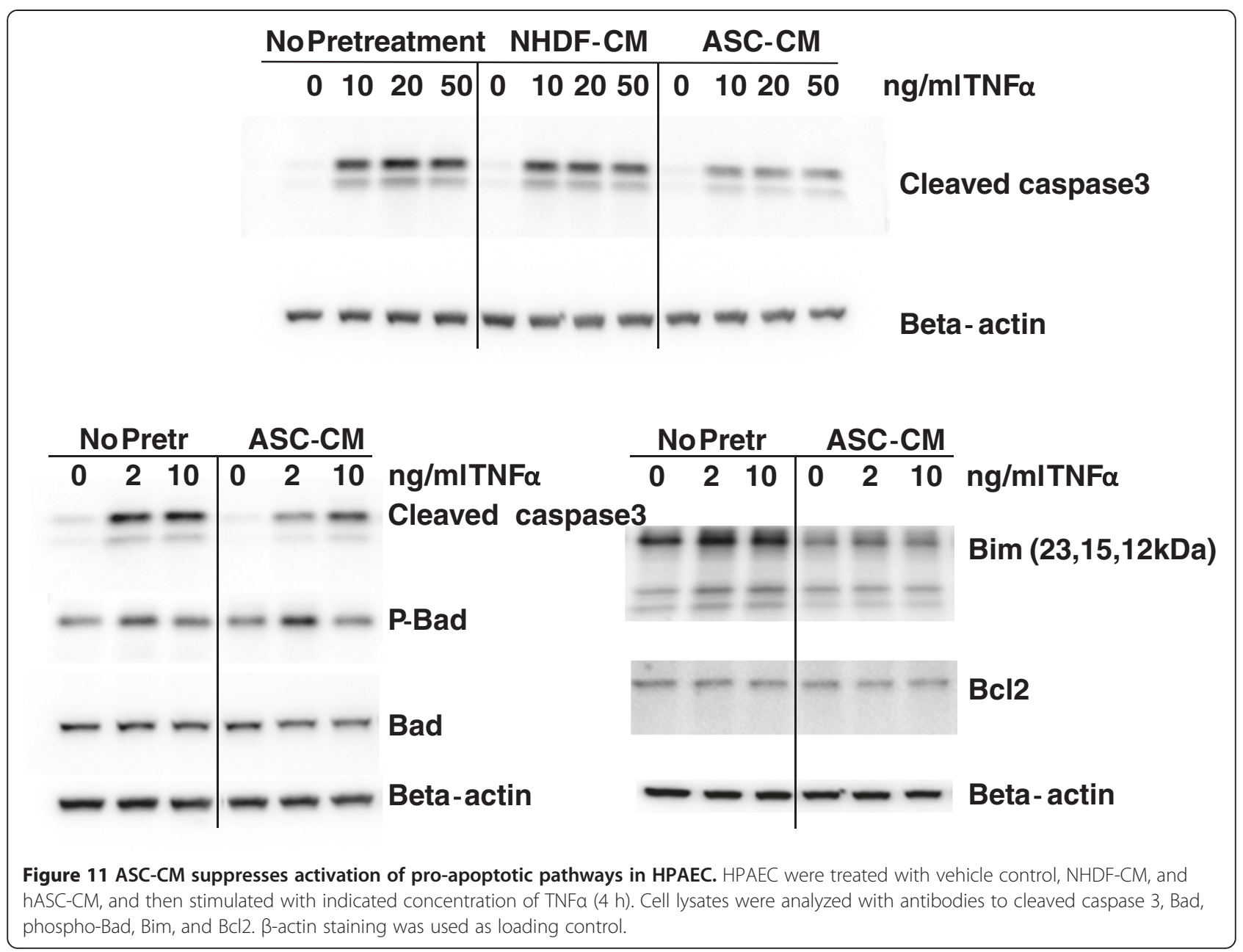

of the beneficial cell-secreted factors. Nonetheless, our data suggest that the ability of neutrophils to cause damage to the parenchyma and epithelium via oxidative burst is attenuated in the mice receiving ASC-CM. Moreover, our in vitro data show that the abilities of endothelium to resist $\mathrm{H}_{2} \mathrm{O}_{2}$-induced barrier dysfunction and TNF-induced proinflammatory and pro-apoptotic changes are enhanced by ASC secreted factors. We show here that the exposure of endothelium to ASC-CM lowers the level of pro-apoptotic protein Bim. All three Bim isoforms are known to induce apoptosis [35]. Bim plays an important role in Bax/Bakmediated cytochrome $\mathrm{C}$ release and activation of caspase cascade [36]. We believe that down-regulation of proapoptotic proteins by ASC-secreted factors is a novel mechanism, contributing to alleviation of endothelial pathology and pulmonary vascular dysfunction. Whether downregulation of pro-apoptotic proteins is observed in ARDS lungs in response to ASC or ASC-CM therapy, is a subject for future research.

In our in vivo model utilizing a single delivery of ASC$\mathrm{CM}$, secreted factors showed somewhat inferior potency compared to ASC, except for protein extravasation into BALF. Increased protein extravasation results from a leaky epithelial barrier, which is likely to be counteracted by ASC-secreted factors, similar to the effect shown on endothelium. Surprisingly, we did not detect a beneficial effect of ASC on LPS-induced protein extravasation. We assume that the host response to ASC engrafted into inflamed lung is likely to be different from the host response to a single delivery of ASC-secreted factors. Specifically, our results show that ASC-CM treatment causes marked reduction of LPS-induced VEGF level in BALF, whereas ASC treatment had little effect on this endpoint. VEGF secreted to airspace may facilitate longterm tissue repair, but also temporarily contribute to the compromise of barrier function. Therefore, the effect of ASC on ARDS may involve an interplay between the resident lung tissue responses and the infused ASC, with the need to analyze temporal factors for the optimization of therapy.

Recently, concentrated microvesicular fraction of the conditioned media from bone marrow-derived MSC was 
shown to alleviate LPS-induced lung injury [37]. However, to achieve an effect comparable to the effect of cell therapy, the vesicular fraction was concentrated from the media conditioned with approximately 4 times the amount of MSC used for injection. On the contrary, in our experiments the media was concentrated from only half the amount of ASC used for injection. These data suggests that either the microvesicle preparation process led to a partial loss of activity, or that bone marrowderived MSC therapy relies to a larger extent on cell-tocell transfer of bioactive material than on bioactive material secretion.

The effects of ASC therapy on lung pathology may include both cellular (e.g., mitochondrial transfer), as have been proposed [26] as well as paracellular (secreted factors) mechanisms. This study indicates that a single dose of factors secreted by ASC-CM is sufficient to limit several indices of ARDS. Future studies should investigate if continuous delivery of ASC-CM has increased efficacy in this and other models of ARDS.

\section{Conclusions}

Systemic administration of ASC conditioned media diminishes LPS-induced lung injury by inhibiting protein extravasation into BALF, neutrophil inflammatory response, secretion of pro-inflammatory cytokines TNF $\alpha$ and IL6, and histopathological changes of the lungs. Exposure of endothelium to factors secreted by ASC attenuates endothelial barrier dysfunction and pro-inflammatory and proapoptotic changes. Suppression of pro-apoptotic pathways is likely to be mediated by the down-regulation of certain pro-apoptotic proteins in endothelium. Our findings provide novel insights into the paracrine mechanisms of ASC's beneficial effects in ARDS.

\section{Abbreviations}

ARDS: Adult respiratory distress syndrome; ASC: Adipose stromal cells; ASC-CM: ASC conditioned media; BALF: Bronchoalveolar lavage fluid; carboxy-DCFH-DA: Carboxy-dichlorofluorescein diacetate; EBM2: Endothelial basal media 2; EGM2-MV: Endothelial growth media 2 for microvascular cells; FITC-dexran: Fluorescein isothiocyanate-dextran; HPAEC: Human pulmonary artery endothelial cells; ICU: Intensive care unit; LPS: Lipopolysaccharide; MSC: Mesenchymal stromal cells; NHDF: Normal human dermal fibroblasts; ROS: Reactive oxygen species; TER: Transendothelial resistance; WBC: White blood cells.
}

\section{Competing interests}

There is a provisional patent filed by KM and NB for the treatment of ARDS with ASC-CM. The authors declare that they have no competing interests.

\section{Authors' contributions}

HL carried out the majority of in vitro and in vivo experiments and was involved in revising the manuscript. CP carried out in vivo experiments and was involved in revising the manuscript. TC carried out in vivo experiments. DT was involved in isolation and characterization of mouse and human ASC used in this manuscript, and manuscript revisions. SM isolated mouse and human ASC. BL helped with in vitro experiments. IP have been involved in conceptual design of the manuscript and manuscript editing. KM participated in study design and coordination and helped to draft the manuscript. NB designed the study, carried out in vivo experiments, performed statistical analysis, and drafted the manuscript. All authors read and approved the final manuscript.

\section{Acknowledgements}

This work was supported by Krannert Institute of Cardiology Endowment Fund (NB), AHA SDG 0930038 N (NB) and 10SDG2720016 (DT), R01 HL105772 (IP, KM) and support from Vascular and Cardiac Center for Adult Stem Cell Therapy and the Cryptic Masons Medical Research Foundation. The authors are grateful to Daria Barwinska and Drs. Yameena Jawed, Reef Hardy, Jie Xie, and $\mathrm{Ru}$ Yi for the technical assistance with some of the experiments.

\section{Author details}

${ }^{1}$ Division of Cardiology, Indiana University, Indianapolis, IN, USA. ${ }^{2}$ Indiana Center for Vascular Biology and Medicine and VC-CAST Signature Center, Indianapolis, IN, USA. ${ }^{3}$ Roudebush Veterans Affairs Medical Center, Indiana University, Indianapolis, IN, USA. ${ }^{4}$ Division of Pulmonary and Critical Care Medicine, Indiana University, Indianapolis, IN, USA.

Received: 24 November 2014 Accepted: 28 January 2015

Published online: 21 February 2015

\section{References}

1. Boyle AJ, Sweeney RM, McAuley DF. Pharmacological treatments in ARDS; a state-of-the-art update. BMC Med. 2013;11:166.

2. Force ADT, Ranieri VM, Rubenfeld GD, Thompson BT, Ferguson ND, Caldwell $\mathrm{E}$, et al. Acute respiratory distress syndrome: the Berlin definition. JAMA. 2012;307:2526-33.

3. Rubenfeld GD. Epidemiology of acute lung injury. Crit Care Med. 2003;31: S276-84.

4. Matthay MA, Ware LB, Zimmerman GA. The acute respiratory distress syndrome. J Clin Invest. 2012;122:2731-40.

5. Fanelli V, Vlachou A, Ghannadian S, Simonetti U, Slutsky AS, Zhang H. Acute respiratory distress syndrome: new definition, current and future therapeutic options. J Thorac Dis. 2013;5:326-34

6. Hayes M, Curley G, Laffey JG. Mesenchymal stem cells - a promising therapy for Acute Respiratory Distress Syndrome. F1000 Med Rep. 2012;4:2.

7. Sueblinvong V, Weiss DJ. Stem cells and cell therapy approaches in lung biology and diseases. Transl Res. 2010;156:188-205.

8. Murphy MB, Moncivais K, Caplan Al. Mesenchymal stem cells: environmentally responsive therapeutics for regenerative medicine. Exp Mol Med. 2013;45:e54.

9. Danchuk S, Ylostalo JH, Hossain F, Sorge R, Ramsey A, Bonvillain RW, et al. Human multipotent stromal cells attenuate lipopolysaccharide-induced acute lung injury in mice via secretion of tumor necrosis factor-alphainduced protein 6. Stem Cell Res Ther. 2011;2:27.

10. Gupta N, Su X, Popov B, Lee JW, Serikov V, Matthay MA. Intrapulmonary delivery of bone marrow-derived mesenchymal stem cells improves survival and attenuates endotoxin-induced acute lung injury in mice. J Immunol. 2007;179:1855-63.

11. Lee JW, Fang X, Gupta N, Serikov V, Matthay MA. Allogeneic human mesenchymal stem cells for treatment of E. coli endotoxin-induced acute lung injury in the ex vivo perfused human lung. Proc Natl Acad Sci U S A. 2009:106:16357-62.

12. Krasnodembskaya A, Song Y, Fang X, Gupta N, Serikov V, Lee JW, et al. Antibacterial effect of human mesenchymal stem cells is mediated in part from secretion of the antimicrobial peptide LL-37. Stem Cells. 2010:28:2229-38

13. Mei SH, McCarter SD, Deng Y, Parker CH, Liles WC, Stewart DJ. Prevention of LPS-induced acute lung injury in mice by mesenchymal stem cells overexpressing angiopoietin 1. PLoS Med. 2007:4:e269.

14. Nemeth K, Leelahavanichkul A, Yuen PS, Mayer B, Parmelee A, Doi K, et al. Bone marrow stromal cells attenuate sepsis via prostaglandin $E(2)$ dependent reprogramming of host macrophages to increase their interleukin-10 production. Nat Med. 2009;15:42-9.

15. Ortiz LA, Dutreil M, Fattman C, Pandey AC, Torres G, Go K, et al. Interleukin 1 receptor antagonist mediates the antiinflammatory and antifibrotic effect of mesenchymal stem cells during lung injury. Proc Natl Acad Sci U S A. 2007;104:11002-7.

16. Strioga M, Viswanathan S, Darinskas A, Slaby O, Michalek J. Same or not the same? Comparison of adipose tissue-derived versus bone marrow-derived mesenchymal stem and stromal cells. Stem Cells Dev. 2012;21:2724-52. 
17. Chien MH, Bien MY, Ku CC, Chang YC, Pao HY, Yang YL, et al. Systemic human orbital fat-derived stem/stromal cell transplantation ameliorates acute inflammation in lipopolysaccharide-induced acute lung injury. Crit Care Med. 2012;40:1245-53.

18. Shin S, Kim Y, Jeong S, Hong S, Kim I, Lee W, et al. The therapeutic effect of human adult stem cells derived from adipose tissue in endotoxemic rat model. Int J Med Sci. 2013;10:8-18.

19. Zhang S, Danchuk SD, Bonvillain RW, Xu B, Scruggs BA, Strong AL, et al. Interleukin 6 mediates the therapeutic effects of adipose-derived stromal/stem cells in lipopolysaccharide-induced acute lung injury. Stem Cells. 2014;32:1616-28.

20. Zhang S, Danchuk SD, Imhof KM, Semon JA, Scruggs BA, Bonvillain RW, et al. Comparison of the therapeutic effects of human and mouse adiposederived stem cells in a murine model of lipopolysaccharide-induced acute lung injury. Stem Cell Res Ther. 2013;4:13.

21. Chang $C L$, Leu $S$, Sung $H C$, Zhen $Y Y$, Cho $C L$, Chen A, et al. Impact of apoptotic adipose-derived mesenchymal stem cells on attenuating organ damage and reducing mortality in Rat sepsis syndrome induced by cecal puncture and ligation. J Transl Med. 2012;10:244.

22. Liang ZD, Yin XR, Cai DS, Zhou H, Pei L. Autologous transplantation of adipose-derived stromal cells ameliorates ventilator-induced lung injury in rats. J Transl Med. 2013;11:179.

23. Sun CK, Yen $\mathrm{CH}$, Lin YC, Tsai TH, Chang LT, Kao YH, et al. Autologous transplantation of adipose-derived mesenchymal stem cells markedly reduced acute ischemia-reperfusion lung injury in a rodent model. J Transl Med. 2011;9:118.

24. Xu J, Qu J, Cao L, Sai Y, Chen C, He L, et al. Mesenchymal stem cell-based angiopoietin-1 gene therapy for acute lung injury induced by lipopolysaccharide in mice. J Pathol. 2008;214:472-81.

25. Dooner MS, Aliotta JM, Pimentel J, Dooner GJ, Abedi M, Colvin G, et al. Conversion potential of marrow cells into lung cells fluctuates with cytokine-induced cell cycle. Stem Cells Dev. 2008;17:207-19.

26. Islam MN, Das SR, Emin MT, Wei M, Sun L, Westphalen K, et al. Mitochondrial transfer from bone-marrow-derived stromal cells to pulmonary alveoli protects against acute lung injury. Nat Med. 2012;18:759-65.

27. Traktuev DO, Merfeld-Clauss S, Li J, Kolonin M, Arap W, Pasqualini R, et al. A population of multipotent CD34-positive adipose stromal cells share pericyte and mesenchymal surface markers, reside in a periendothelial location, and stabilize endothelial networks. Circ Res. 2008:102:77-85.

28. Sroussi HY, Lu Y, Zhang QL, Villines D, Marucha PT. S100A8 and S100A9 inhibit neutrophil oxidative metabolism in-vitro: involvement of adenosine metabolites. Free Radic Res. 2010;44:389-96.

29. Bogatcheva NV, Adyshev D, Mambetsariev B, Moldobaeva N, Verin AD Involvement of microtubules, p38, and Rho kinases pathway in 2methoxyestradiol-induced lung vascular barrier dysfunction. Am J Physiol Lung Cell Mol Physiol. 2007:292:L487-99.

30. Houlihan DD, Mabuchi Y, Morikawa S, Niibe K, Araki D, Suzuki S, et al. Isolation of mouse mesenchymal stem cells on the basis of expression of Sca-1 and PDGFR-alpha. Nat Protoc. 2012;7:2103-11.

31. Zinkel S, Gross A, Yang E. BCL2 family in DNA damage and cell cycle control. Cell Death Differ. 2006;13:1351-9.

32. Klopp AH, Zhang Y, Solley T, Amaya-Manzanares F, Marini F, Andreeff M, et al. Omental adipose tissue-derived stromal cells promote vascularization and growth of endometrial tumors. Clin Cancer Res. 2012;18:771-82.

33. Tatsumi K, Ohashi K, Matsubara Y, Kohori A, Ohno T, Kakidachi H, et al. Tissue factor triggers procoagulation in transplanted mesenchymal stem cells leading to thromboembolism. Biochem Biophys Res Commun. 2013;431:203-9.

34. Wei X, Du Z, Zhao L, Feng D, Wei G, He Y, et al. IFATS collection: the conditioned media of adipose stromal cells protect against hypoxiaischemia-induced brain damage in neonatal rats. Stem Cells. 2009;27:478-88

35. O'Connor L, Strasser A, O'Reilly LA, Hausmann G, Adams JM, Cory S, et al. Bim: a novel member of the $\mathrm{BCl}-2$ family that promotes apoptosis. Embo J. 1998;17:384-95.

36. Adams JM, Cory S. BCl-2-regulated apoptosis: mechanism and therapeutic potential. Curr Opin Immunol. 2007;19:488-96

37. Zhu YG, Feng XM, Abbott J, Fang XH, Hao Q, Monsel A, et al. Human mesenchymal stem cell microvesicles for treatment of Escherichia coli endotoxin-induced acute lung injury in mice. Stem Cells. 2014:32:116-25.

\section{Submit your next manuscript to BioMed Central and take full advantage of:}

- Convenient online submission

- Thorough peer review

- No space constraints or color figure charges

- Immediate publication on acceptance

- Inclusion in PubMed, CAS, Scopus and Google Scholar

- Research which is freely available for redistribution

Submit your manuscript at www.biomedcentral.com/submit 